\title{
Morphometric analysis of mental foramen in human dry mandibles of nepalese population
}

\author{
Muna Kadel'1, Bishwo P Sedhain ${ }^{2}$, Prakash M S Dangol ${ }^{3}$ \\ ${ }^{1}$ Lecturer, ${ }^{3}$ Professor, Department of Anatomy, KIST Medical College, Lalitpur, ${ }^{2}$ Oral and Maxillofacial Surgeon, \\ Department of Oral Surgery, Om Samaj Dental Hospital, Kathmandu, Nepal
}

Background: Mental foramina are located bilaterally in the antero-lateral aspect of the body of mandible. It transmits mental nerve, and vessels. The location, shape, size, direction and number of mental foramen in human mandibles are subject of variation. The knowledge of it is applicable in endodontics, surgery and anesthesia. Aims and Objective: To establish the location, shape, size, direction and incidence of mental foramen (MF) in dry human mandibles of Nepalese population. Materials and Methods: One hundred dry human mandibles of unknown age and sex were selected randomly. Shape, size, position of MF with respect to tooth and other anatomical landmark were determined. Paired t-test was used for specific statistical analysis. Results: In most cases $(61 \%)$, the MF was oval in shape \& situated below the apex of second premolar $(58 \%$ on right side and $69 \%$ on left side). Various parameters investigated were, the horizontal distance between (1) base of mandible and MF was $12.24 \mathrm{~mm}$ on right and $12.26 \mathrm{~mm}$ on the left, (2) alveolar margin and MF was $13.95 \mathrm{~mm}$ on right and $13.75 \mathrm{~mm}$ on left (3) symphysis menti of mandible and MF was $26.71 \mathrm{~mm}$ on right and $26.49 \mathrm{~mm}$ on left, (4) posterior border of mandible and MF was $65.34 \mathrm{~mm}$ on right and $65.68 \mathrm{~mm}$ on left. Conclusion: By the knowledge of position, shape, size, direction and distance of the mental foramen from various landmarks and the presence of the accessory foramen may be of much use to dental surgeons.

\section{Access this article online}

Website:

http://nepjol.info/index.php/AJMS

DOI: 10.3126/ajms.v7i6.15697

E-ISSN: 2091-0576

P-ISSN: 2467-9100

Key words: Anatomy, Mandible, Premolar, Nerve

\section{INTRODUCTION}

Mental foramina are located bilaterally in the antero-lateral aspect of the body of mandible. It transmits mental nerve, and vessels. Mental nerve is a branch of inferior alveolar nerve, which carries general sensation from the lower lip and the labial mucosa. Inferior alveolar nerve branches into the mental nerve and incisive nerve near the mental foramen. Mental nerve ultimately leaves the mandible through the mental foramen (MF) and the incisive nerve, which remains within the bone, supplies the mandibular incisors and canine teeth. ${ }^{1}$ Position of MF varies among racial groups and genders. ${ }^{2,3}$ The most common position of the MF is in-line with the longitudinal axis of the $2^{\text {nd }}$ premolar tooth followed by a location between the $1^{\text {st }}$ and second pre-molar teeth. ${ }^{1}$
MF lies midway between the upper and lower borders of mandible in adult and come to lie near to the superior border after teeth are lost. It is directed anteriorly before the fusion of mandible and directed posteriorly after 2-3 years of age. ${ }^{4}$ The shape of mental foramen varies from round in most of the cases to oval in fewer cases. ${ }^{5}$ The presence and variations of accessory mental foramen is also reported by different researchers. ${ }^{6,7}$

Mental foramen is an important landmark at the time of surgical intervention in the mental region of mandible and during local anesthesia. The knowledge of the position of $\mathrm{MF}$ is also important for endodontics (root canal treatment and apiecetomy), implant placement, fracture reduction and orthognathic surgery. The mental nerve could be injured during surgical procedures, resulting in paraesthesia or 
anesthesia. Generally the mental foramen is difficult to locate as it cannot be clinically visualized and palpated. ${ }^{8}$

\section{MATERIALS AND METHODS}

This is a cross-sectional and multicenter study, which was conducted in the Department of Anatomy, KIST Medical College and Maharajgunj Medical Campus, Kathmandu in 100 dry human mandibles of unknown age and sex. At $95 \%$ confidence level, assuming standard deviation of distance MF from symphysismenti is $5.07 \mathrm{~mm}^{9}$ and allowing maximum tolerable error of 1 , the sample size calculated is at least 99 dry human mandibles. Hence, 100 bones were included among which all the mandibles showed bilateral presence of mental foramen. All the samples were stored in a well ventilated and dry condition for about five years. Bones were found clean without any damage.

Mandibles were selected by simple random sampling method by using lottery method. Mandibles of children whose mental foramen is near to the inferior border and that of old age with resorbed alveolar crest were excluded. The number, shape and direction of mental foramen were determined by visual examination. The size and location was examined with the help of digital vernier caliper and their mean value was obtained. Location of MF was marked by using following parameters: (1) Distance from inferior border of the mandible to MF (2) Distance from alveolar margin to MF (3) Distance from symphysismenti to MF (Figure 1) (4) Distance from posterior border of the ramus of mandible to MF. The position of MF was noted in relation to mandibular tooth. The posterosuperior, superior, lateral, antero-superior, posterior or anterior direction of the opening of MF recorded by previous researchers was verified in this study by inserting a probe into the foramen.

Study was conducted after taking ethical clearance on date $31^{\text {st }}$ march 2015 with IRC No: 0053/2014/15 from the Head of the Department of Anatomy and other concerned authorities of both institutes (KIST Medical College and Maharajgunj Medical Campus). SPSS version 20 was used for data entry and analysis. The p-value $<0.05$ was considered statistically significant. Paired ' $t$ '-test was used to compare the mean value of right and left sides of mandible.

\section{RESULTS}

Hundred dry human mandibles of unknown age and sex were examined for the presence of mental foramen. Mental foramen was present bilaterally in all the hundred samples.

\section{Shape of MF}

On right side it was oval in $61 \%$ of mandibles and round in $39 \%$ of mandibles. Similarly on left side it was oval in $50 \%$ and round in $50 \%$ of mandibles as shown in Chart 1.

\section{Size of MF}

Mean horizontal diameter was $3.01 \mathrm{~mm}$ on right side and $2.88 \mathrm{~mm}$ on left side with range of 1.01-5.02 mm. Horizontal diameters between right and left side was statistically significant $(\mathrm{P}=0.044)$. Mean vertical diameter was $2.29 \mathrm{~mm}$ on both right and left side with range of $0.99-4.03 \mathrm{~mm}$.

Frequency of the position of MF in relation to mandibular teeth socket

The most frequent position of MF in relation to the tooth was in line with the longitudinal axis of $2^{\text {nd }}$ premolar for both right (58\%) and left (69\%) sides. The second common position was in between the first and second premolar teeth as described in Table 1 and Chart 2.

\section{Position of mental foramen}

Position of mental foramenin relation to various parameters like horizontal distance from (1) base of mandible and MF was $12.24 \mathrm{~mm}$ on right and $12.26 \mathrm{~mm}$ on the left, (2) alveolar

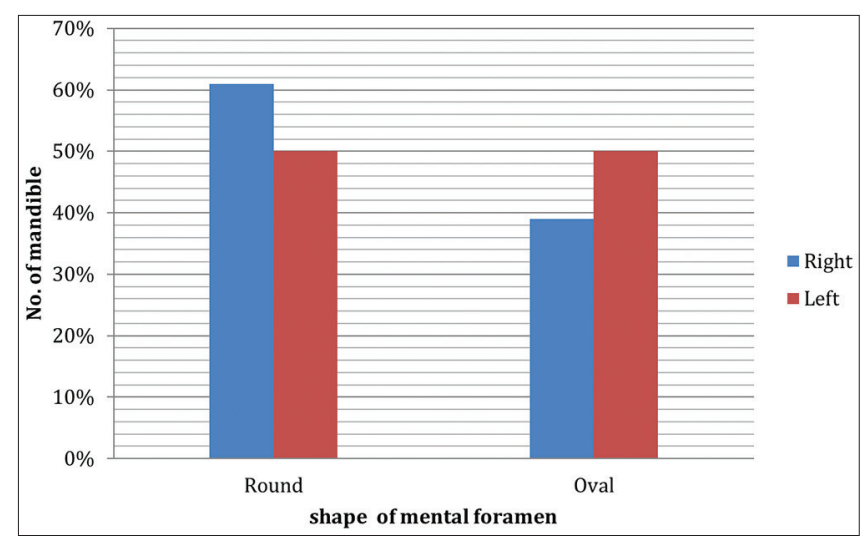

Chart 1: Bar diagram representing the shape of mental foramen

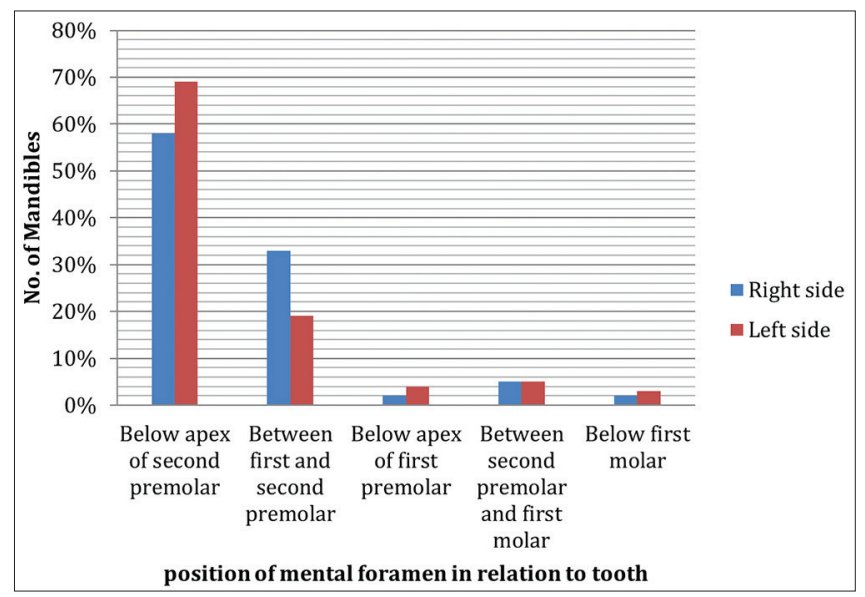

Chart 2: The position of MF in relation to mandibular teeth socket 
margin and $\mathrm{MF}$ was $13.95 \mathrm{~mm}$ on right \& $13.75 \mathrm{~mm}$ on left (3) symphysismenti of mandible and MF was $26.71 \mathrm{~mm}$ on right and $26.49 \mathrm{~mm}$ on left, (4) posterior border of mandible and MF was $65.34 \mathrm{~mm}$ on right and $65.68 \mathrm{~mm}$ on left been described in Table 2. There was no significance difference between the position of MF on left and right side of mandible which was compared by using paired t test.

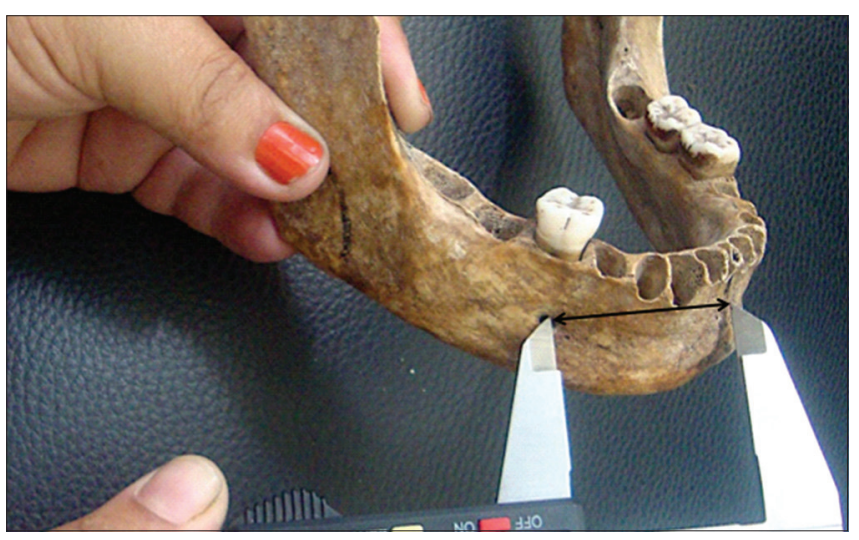

Figure 1: Distance from symphysismenti to MF (D3)

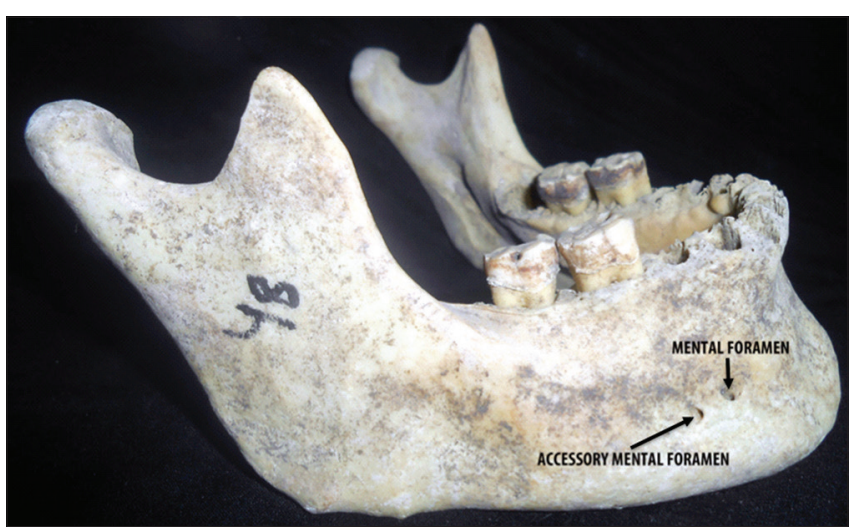

Figure 2: Mental foramen \& accessory mental foramen

\begin{tabular}{lcc}
\multicolumn{3}{l}{ Table 1: Frequency of the position of mental } \\
foramen in relation to mandibular teeth socket \\
\hline Position & $\begin{array}{c}\text { Right } \\
\text { side } \%\end{array}$ & $\begin{array}{c}\text { Left } \\
\text { side } \%\end{array}$ \\
\hline Below apex of second premolar & 58 & 69 \\
Between first and second premolar & 33 & 19 \\
Below apex of first premolar & 2 & 4 \\
Between second premolar and first molar & 5 & 5 \\
Below first molar & 2 & 3 \\
\hline
\end{tabular}

The direction of exit of the MF was posterosuperior in $65 \%$, followed by superior of the mandibles as shown in Table 3.

\section{Incidence of accessory mental foramen}

Presence of accessory mental foramen (AMF) was observed in 6 out of 100 mandibles (Figure 2). Out of six mandibles, three AMF were present on the right and three on the left side. Interestingly, none of the mandibles had bilateral accessory mental foramen.

\section{DISCUSSION}

The proper identification of exact location of mental foramen is important in both diagnostic and surgical procedure. ${ }^{8}$ Anatomically, the mental foramen is the opening of the mandibular canal. This study showed that the most common position of the MF was below the apex of second premolar, which was similar with some studies. ${ }^{1,6}$ Some authors have mentioned that the most common position of mental foramen is between the apices of mandibular first and second premolar ${ }^{10,11}$ but this was found to be second common position in this study supported by the study of Dipti A. Nimje et al. ${ }^{1,11,12}$ The position of the mental foramen varies depending on various factors like symmetry of mental triangle, morphology and maturity of the human mandible, bone remodeling activity and anthropologic features of the facial skeleton in different populations. In this study, majority of mental foramina were oval in shape i.e., $55.5 \%$ and only $44.5 \%$ had rounded shaped which was similar to study conducted by Siddiqui AU et al, ${ }^{13}$ Shaik HS et al, ${ }^{14}$ and Eboh DE. ${ }^{1}$

In contrast to this study Singh $\mathrm{R}$ et $\mathrm{al}^{6}$ found $6 \%$ oval and $94 \%$ round mental foramen. In the study by Ilayperuma I et $\mathrm{al}^{15}$ mean transverse diameter of mental foramen on right side was $3.26 \mathrm{~mm}$ and on left side $3.41 \mathrm{~mm}$ while the mean vertical diameter was $2.45 \mathrm{~mm}$ on right side and $2.60 \mathrm{~mm}$ on left side. In the study of Agrawal DR et $\mathrm{al}^{9}$ findings were as, mean transverse diameter on right side $3.33 \mathrm{~mm}$ and on left side $3.25 \mathrm{~mm}$ and mean vertical diameter on right side $2.15 \mathrm{~mm}$ and on left side $2.13 \mathrm{~mm}$. In this study mean transverse diameter was found to be $3.11 \mathrm{~mm}$ on right side and $2.88 \mathrm{~mm}$ on left side. The mean vertical diameter was $2.29 \mathrm{~mm}$ on both right and left side, which

\begin{tabular}{|c|c|c|c|c|}
\hline \multirow[t]{2}{*}{ Characteristics } & \multicolumn{2}{|c|}{ Mean \pm SD $(\mathrm{mm})$} & \multirow[t]{2}{*}{$p$ value } & \multirow[t]{2}{*}{ t value } \\
\hline & Right side & Left side & & \\
\hline Distance from base of mandible (D1) & $12.24 \pm 1.30$ & $12.26 \pm 1.23$ & 0.882 & -0.149 \\
\hline Distance from alveolar margin (D2) & $13.95 \pm 1.73$ & $13.75 \pm 1.83$ & 0.085 & 1.738 \\
\hline Distance from symphysismenti (D3) & $26.71 \pm 1.96$ & $26.49 \pm 2.11$ & 0.124 & 1.553 \\
\hline Distance from the posterior border of ramus of mandible (D4) & $65.34 \pm 4.71$ & $65.68 \pm 4.24$ & 0.177 & -1.360 \\
\hline
\end{tabular}


Table 3: Orientation of mental foramen

\begin{tabular}{lcc}
\hline Characteristic & Right side & Left side \\
\hline Posterosuperior & $65 \%$ & $65 \%$ \\
Posterior & $6 \%$ & $10 \%$ \\
Superior & $26 \%$ & $23 \%$ \\
Anterior & $2 \%$ & $0 \%$ \\
Anterosuperior & $1 \%$ & $2 \%$ \\
\hline
\end{tabular}

was in consistent with the study of Dipti A. Nimje et al. ${ }^{12}$ Direction of opening of the mental foramen was postero superiorly in majority of the subjects $(65 \%)$. This was in agreement with previous studies [Deepa Rani \& Sandeep] ${ }^{9}$ and Udhaya et al. ${ }^{16}$

In the present study the distance from base of mandible to the mental foramen (D1) was12.24 $\pm 1.30 \mathrm{~mm}$ on right side and $12.26 \pm 1.23 \mathrm{~mm}$ on left side. The distance between mental foramen and alveolar margin (D2) was $13.95 \pm 1.73 \mathrm{~mm}$ on right side and on left side it was $13.75 \pm 1.83 \mathrm{~mm}$. The distance between mental foramen and symphysismenti (D3) was $26.71 \pm 1.96 \mathrm{~mm}$ on right side and on left side it was $26.49 \pm 2.11 \mathrm{~mm}$. The distance between mental foramen and posterior border of ramus of mandible (D4) was $65.34 \pm 71 \mathrm{~mm}$ on right side while on left side it was $65.68 \pm 4.24 \mathrm{~mm}$. These data were similar to the findings of Dipti A. Nimje et al. ${ }^{12}$ The findings of Singh R et al (2010) ${ }^{6}$ differs from the present study.

In this study six accessory mental foramina were found. Three AMF on the left side and three on the right side, which indicates $3 \%$ on the right side and 3\% on the left side with $6 \%$ of total incidence. Imada et al, ${ }^{17}$ also studied in 100 mandible and found six accessory mental foramen, three on right and left side. The findings of Shukla RK et $\mathrm{al}^{18}$ in 96 mandibles a single accessory mental foramen was identified in $4.17 \%$ of the sample 7 reported $6.62 \%$ of the mandibles possessed accessory mental foramina. Naitoh Munetaka et $\mathrm{al}^{19}$ said the accessory mental foramen was observed in $7 \%$ of patients. These findings were similar with the present study. This study shows no significant difference between the position and morphometry of mental foramen on right and left side of the mandible compared by using paired $t$ test. The findings of this study were similar to that the study carried out by Dipti A. Nimje et al. ${ }^{12}$

\section{CONCLUSION}

The present study adds information to the literature concerning the location and morphology of mental foramen in Nepalese population. The most common location of the MF in this study is below second premolar but many reported between first and second molar. The presence of accessory mental foramen is less. The findings obtained from this study is similar to that of different researchers different parts of India. On top of that most of findings of this study are very much similar to the findings of Singh $\mathrm{R}$ et $\mathrm{al}^{6}$ conducted in Maharashtra. But the knowledge of both mental foramen and accessory mental foramen helps the surgeon to avoid paresthesia and hemorrhage during surgical intervention and helps for better patient care.

\section{ACKNOWLEDGMENT}

I am immensely grateful towards Prof. Dr. Kishore Singh Basnet, Ms Shanta Hada, Lecturer Department of Anatomy, KIST Medical College and Dr. Nirju Ranjit, Associate Professor and Head of Department of Anatomy, Maharajgunj Medical Campus, Kathmandu for their support and valuable suggestions. I am thankful to Prof Dr. Amita Pradhan and Mr. Padam Dahal Department of Community Medicine, KIST Medical College, Imadol for their suggestions and help in statistical analysis.

\section{REFERENCES}

1. Eboh DE and Oliseh El. Analysis of mental foramen in dry human mandibles of adult Nigerians. Afr $\mathrm{J}$ Med Med Sci 2014;43(2):107-113.

2. Kumar V, Hunsigi P, Kaipa BR and Prasanna MD. Radiographic localization of mental foramen in Northeast and South Indian ethnic groups of Indian population. J Contemp Dent Pract 2014;15(6):766-769.

3. Chandra A, Singh A, Badni M, Jaiswal R and Agnihotri A. Determination of sex by radiographic analysis of mental foramen in North Indian population. J Forensic Dent Sci 2013;5(1):52-55.

4. Ngeow WC, Dionysius DD, Ishak $\mathrm{H}$ and Nambiar P. Effect of Ageing Towards Location and Visibility of Mental Foramen on Panoramic Radiographs. Singapore Dental Journal 2010;31(1):15-19.

5. Gupta $S$ and Soni JS. Study of anatomical variations and incidence of mental foramen and accessory mental foramen in dry human mandibles. Natl J Med Res 2012;2(1):28-30.

6. Singh R and Srivastav A. Study of position, shape, size and incidence of mental foramenand accessory mental foramen in indian adult human skulls. Int J Morphol 2010;28(4):1141-1146.

7. Paraskevas G, Mavrodi A and Natsis K. Accessory mental foramen: an anatomical study on dry mandibles and review of the literature. Oral Maxillofac Surg 2015;19(2):177-181.

8. Greenstein $G$ and Tarnow D. The mental foramen and nerve: clinical and anatomical factors related to dental implant placement: a literature review. J Periodontol 2006;77(12):1933-1943.

9. Agarwal DR and Gupta SB. Morphometeric Analysis of Mental Foramen in Human Mandibles of South Gujarat. 2011.

10. Von Arx T, Friedli M, Sendi P, Lozanoff $S$ and Bornstein MM. Location and dimensions of the mental foramen: a radiographic analysis by using cone-beam computed tomography. J Endod 2013;39(12):1522-1528.

11. Kqiku L, Weiglein A, Kamberi B, Hoxha V and Meqa K. Position of the mental foramen in Kosovarian population. Collegium antropologicum 2013;37(2):545-549.

12. Nimje DA, Wankhede HA and Hosmani PB. Morphometric 
study of the mental foramen in dry adult human mandibles. International Journal of Recent Trends in Science And Technology 2014;12(1):47-49.

13. Siddiqui AU, Daimi SR, Mishra PP, Doshi SS, Date JY and Khurana G. Morphological and morphometric analysis of mental foramen utilizing various assessment parameters in dry human mandibles. Int J Stud Res 2011; 1(1):19-22

14. Shaik HS, Shepur MP, Desai ST, Thomas ST, Maavishettar GF and Haseena S. Morphological and morphometric study of mental foramen south Indian mandibles. Indian J Med Healthcare 2012; 1(3):64-66.

15. Ilayperuma I, Nanayakkara $G$ and Palahepitiya N. Morphometric Analysis of the Mental Foramen in Adult Sri Lankan Mandibles. International Journal Of Morphology 2009;27(4):1019-1024

16. Udhaya K, Saraladevi KV and Sridhar J. The morphometric analysis of the mental foramen in adult dry human mandibles: a study on the South Indian population. J Clin Diagn Res 2013;7(8):1547-1551.

17. ImadaTSN, Fernandes LMPdS, Centurion BS, Oliveira-Santos $C$, Honório HM and Rubira-Bullen IRF. Accessory mental foramina: prevalence, position and diameter assessed by cone-beam computed tomography and digital panoramic radiographs. Clin Oral Implants Res 2014;25(2):e94-e99.

18. Shukla RK, Gupta P, Hussein M, Hussain F and Singh AB. Morphometric measurement of mental foramen in dry human mandible in north indian population. Int $\mathrm{J}$ Anat Res 2015;3(1):899-905.

19. Naitoh M, Hiraiwa $Y$, Aimiya $H$, Gotoh $K$ and Ariji E. Accessory mental foramen assessment using cone-beam computed tomography. Oral Surgery, Oral Medicine, Oral Pathology, Oral Radiology, and Endodontology 2009;107(2):289-294.

\footnotetext{
Authors Contribution:

MK - Concept and design of the study, reviewed the literature, manuscript preparation and critical revision of the manuscript. BPS - Concept, collected data and review of literature and helped in preparing first draft of manuscript. PMSD - Concept of study and review of study.
} 